\title{
An Improved Uncertainty Measure Theory Based on Game Theory Weighting
}

\author{
Hujun He $\mathbb{D}^{1},{ }^{1,2,3}$ Chong Tian, ${ }^{1}$ Gang Jin, ${ }^{1}$ and Le $\mathrm{An}^{1}$ \\ ${ }^{1}$ School of Earth Science and Resources, Chang'an University, Xian 710054, China \\ ${ }^{2}$ Key Laboratory of Western Mineral Resources and Geological Engineering, Ministry of Education, Xian 710054, China \\ ${ }^{3}$ State Key Laboratory of Water Resource Protection and Utilization in Coal Mining, Shenhua Group Co., Ltd., Beijing 100011, China
}

Correspondence should be addressed to Hujun He; hsj2010@chd.edu.cn

Received 4 April 2019; Revised 9 May 2019; Accepted 19 May 2019; Published 27 May 2019

Academic Editor: Elena Zaitseva

Copyright (C) 2019 Hujun He et al. This is an open access article distributed under the Creative Commons Attribution License, which permits unrestricted use, distribution, and reproduction in any medium, provided the original work is properly cited.

\begin{abstract}
In the application of uncertainty measure theory, the determination method of index weight mainly includes the subjective weight determination method and the objective weight determination method. The subjective weight determination method has the disadvantages affected by the subjective preference of the decision-maker. The objective weight determination method often ignores the participation degree of the decision-maker, and when using the uncertainty measure evaluation model to perform multi-index classification evaluation, the credible degree recognition criterion is often used as the attribute recognition of the object to be measured, because the credible degree is taken by the subjective people, and the different values of different people have a great influence on the evaluation results. In order to solve the above problems in the uncertainty measure theory, this paper used the combination weighting of game theory to determine the optimal weight. At the same time, the credible degree recognition criterion was improved on the basis of the concept of minimum uncertainty measure distance, and a game theory-improved uncertainty measure optimization model was proposed. Finally, the validity of the model was proven by a case.
\end{abstract}

\section{Introduction}

Uncertainty measure theory $[1,2]$ is a mathematical method for studying uncertainty information. It can quantitatively describe the size of a thing that is in an uncertainty state or has uncertainty. Since the uncertainty measure model was put forward, it has been widely used in various fields. But, in the practical application process, the authors found that there are two defects in the uncertainty measure theory. On one hand, the index weight is determined. So far, the determination of index weight is roughly divided into the subjective weight algorithm and the objective weighting method $[3,4]$. The subjective weighting method is the method in which the decision-maker directly gives preference information, such as Analytic Hierarchy Process (AHP) [5], minimum square method [6], and Delphi method [7]. The objective weighting method is a method on the basis of decision matrix information, such as entropy method [8], multiobjective optimization method [9], principal component analysis method [10], and scheme closeness degree [11]. In actual decision-making, due to the complexity of the decision-making problem, it is difficult to agree with the actual situation by relying solely on the subjective judgment of the decision-maker or the weight directly given by the objective algorithm. On the other hand, it is the criterion of attribute recognition. At present, in the process of applying the uncertainty measure theory, the credible degree criterion is mainly used to identify and determine the classification level of the judged object. Since the credible degree $\lambda$ is artificially determined, when the credible degree $\lambda$ is taken to be of different values, the different discrimination results will be obtained and sometimes even get the opposite judgment or classification results. Therefore, in order to avoid the above problems in the use of the model, based on the existing subjective and objective weight solving models, this paper introduced the game weighting model and put forward an uncertainty measure model to improve the credible degree recognition criteria. The effectiveness of the algorithm is proven by an example. 


\section{Improved Uncertainty Measure Theory}

Uncertainty measure theory is the base of improved uncertainty measure theory. First, uncertainty measure model of the research objects is established based on uncertainty measure theory. Then, the single index measure function of each discriminant index is established, and the uncertainty measure value of each evaluation index is calculated. Moreover, the weight of each discriminant index is determined by the combination weighting model based on game theory, and the multiple index comprehensive measure of the discriminant object is calculated. At last, the category of the object to be measured is determined based on the uncertainty measure distance.

2.1. Establishment of Discriminant Index System for the Research Objects. The influencing factors of the research object are analyzed and the discriminant index set for the research objects is established. $x_{1}, x_{2}, \ldots, x_{n}$ are a set of $n$ objects to be evaluated, represented as $X=\left\{x_{1}, x_{2}, \ldots, x_{n}\right\}$, which is termed as the domain. Each evaluation object has $m$ one-way evaluation index spaces, represented as $I=\left\{I_{1}, I_{2}, \ldots, I_{m}\right\}$, with $x_{i j}$ being denoted as the observed value of the object $x_{i}$ under the index $I_{j}$.

2.2. Classification of Samples. $U=\left\{C_{1}, C_{2}, \ldots, C_{p}\right\}$ is set as an evaluation space, wherein $C_{k}$ represents the $k$ evaluation level, and the $k$ level is higher than the $k+1$ level; that is, $C_{k}>C_{k+1}$.

2.3. Uncertainty Measure of Single Index. When the observed value $x_{i j}$ of the index $I_{j}$ for the object $x_{i}$ is different, this index makes the level of the evaluation level of $x_{i}$ different, and the $C_{k}$ degree of the $k$ evaluation level of $x_{i j}$ is a set of $\mu_{i j k}=$ $\mu\left(x_{i j} \in C_{k}\right)(i=1,2, \ldots, n ; j=1,2, \ldots, m ; k=1,2 \ldots, p)$. As a measure, it must meet $0 \leq \mu\left(x_{i j} \in C_{k}\right) \leq 1(i=$ $1,2, \ldots, n ; j=1,2, \ldots, m ; k=1,2, \ldots, p)$, and

$$
\mu\left(x_{i j} \in U\right)=1 \quad(i=1,2, \ldots, n ; j=1,2, \ldots, m)
$$

$\mu_{i j k}$ is uncertainty measure; the single index evaluation matrix of the object $I_{i}$ is

$$
\left(\mu_{i j k}\right)_{m \times p}=\left[\begin{array}{cccc}
\mu_{i 11} & \mu_{i 12} & \cdots & \mu_{i 1 p} \\
\mu_{i 21} & \mu_{i 22} & \cdots & \mu_{i 2 p} \\
\vdots & \vdots & \vdots & \vdots \\
\mu_{i m 1} & \mu_{i m 2} & \cdots & \mu_{i m p}
\end{array}\right]
$$

\subsection{Combination Weighting Model Based on Game Theory.} The combination weighting of game theory is different from the traditional simple linear combination weighting. Its central idea is to "coordinate conflicts and maximize benefits," that is, to comprehensively consider the relationship between the indexes, balance the subjective and objective weights, and find the optimization of weights $[12,13]$. The basic algorithm is as follows.

(1) Construction of the basic weight vector set. Assuming that the $H$ weight values are obtained using the $H$ weighting method, the basic weight vector set of the $H$ method is

$$
w_{k}=\left(w_{k 1}, w_{k 2}, \cdots w_{k n}\right), \quad k=1,2, \ldots, H
$$

Any linear combination of $H$ weight vectors is

$$
w=\sum_{k=1}^{H} a_{k} w_{k}^{T}, \quad a_{k}>0
$$

where $a_{k}$ is linear combination coefficient; $w$ is a comprehensive weight value of $H$ weight set.

(2) The optimal combination weight. In order to find the balance in the different weights, the optimal effect weight vector $W$ is obtained. In the calculation process, it can be converted into an optimization of the weight coefficient $a_{k}$ to minimize the deviation between $w$ and differences $w_{k}$. The calculation formula is as follows:

$$
\begin{aligned}
\min \left\|\sum_{j=1}^{H} a_{j} W_{j}^{T}-W_{i}^{T}\right\| & \\
& i=1,2, \ldots, H ; j=1,2, \ldots, H
\end{aligned}
$$

From the differential properties of the matrix, the firstorder derivative condition for the optimization of (5) is

$$
\sum_{j=1}^{H} a_{j} W_{i} W_{j}^{T}=W_{i} W_{i}^{T}
$$

By solving the equation, the combination coefficient $\left[a_{1}, a_{2}, \ldots, a_{H}\right]$ can be obtained, and it can be normalized;

$$
a_{k}^{*}=\frac{a_{k}}{\sum_{k=1}^{H} a_{k}}
$$

is obtained. The final combination weight is

$$
W=\sum_{k=1}^{H} a_{k}^{*} W_{k}^{T}, \quad k=1,2, \ldots, H
$$

2.5. Integrated Evaluation System. According to the index weightings determined, a comprehensive multiple-index measure for evaluating the object $\mu_{i k}=\sum_{j=1}^{m} w_{j} \mu_{i j k}(i=$ $1,2, \ldots, n ; j=1,2, \ldots, m ; k=1,2, \ldots, p)$ is obtained, where if $0 \leq \mu_{k} \leq 1, \sum_{k=1}^{p} \mu_{i k}=1$, then $\mu_{i k}$ is the uncertainty measure and $\left\{\mu_{i 1}, \mu_{i 2}, \ldots, \mu_{i p}\right\}$ is the comprehensive multipleindex evaluation uncertainty measure vector of $x_{i}$.

2.6. Evaluation Criterion. The classification of the evaluation level is orderly, and $C_{k}$ of $k$ evaluation levels is better than $C_{k+1}$ of $k+1$ evaluation levels. Therefore, the maximum measure identification criterion is not suitable, and the confidence recognition criterion is used. $\lambda$ is set at a credible degree $\left(\lambda \geq 0.5\right.$, usually a value of 0.6 or 0.7 is taken), $k_{0}=$ $\min \left(k: \sum_{l=1}^{k_{p}} \mu_{i l} \geq \lambda, 1 \leq l \leq k\right)$, and $C_{k_{0}}$ is considered for the $k_{0}$ evaluation level of $x_{i}$ [14-20]. 
2.7. Calculation of Uncertainty Measure Distance. In order to reduce the influence of artificial subjective factors, the credible degree recognition criteria are optimized on the basis of the uncertainty measure distance, and the category of the object to be measured is determined by the minimum uncertainty measure distance. In the hierarchical space $U$, $Q_{1}=(1,0, \ldots, 0), Q_{2}=(0,1, \ldots, 0), \ldots, Q_{k}=(0,0, \ldots, 1)$ is set as the uncertainty measure of each classification level, the minimum uncertainty measure distance $d_{k}(k=1,2, \ldots, p)$ is the Euclidean distance from the multiple indexes comprehensive measure $\mu_{i k}$ to the classification level $Q_{k}$, and

$$
d_{k}=\left[\left(u_{i 1}-0\right)^{2}+\left(u_{i 2}-0\right)^{2}+\cdots\left(u_{i k}-1\right)^{2}\right]^{0.5}
$$

\subsection{Identification of Classification Level for the Objects to} Be Evaluated. The uncertainty measure distance $d_{k}(k=$ $1,2, \ldots, p)$ is compared; if $k_{0}=\min d_{i}(1 \leq i \leq k ; k=$ $1,2, \ldots, p)$, the objects to be evaluated are considered to be the closest to the classification pattern system, so the classification level of the objects $x_{i}$ to be evaluated belongs to $C_{k_{0}}[20-23]$.

\section{A Case}

The paper selects the data of Hanqiao typical abandoned mines in Jiawang district of Xuzhou provided by Ting Li [24] as the research object. Multiple indices related to the groundwater pollution risk of abandoned mines are considered in the following evaluation. Each index is subdivided into three aspects, which are the risk of pollution sources, the risk of pollution channel, and the hazard of the pollution receptors. Individual aspects are determined by multiple parameters. Qualitative indices are evaluated by semiquantitative methods, and quantitative indices are evaluated using measured values. The criteria used for classification and valuation are presented in Table 1. Each evaluation index was classified and valued, and the evaluation set is $\left\{C_{1}, C_{2}, C_{3}\right\}$. Finally, the evaluation indices are assigned levels: I (high risk), II (medium risk), and III (low risk). The basic situations of three typical abandoned mines zones are shown in Table 2.

3.1. Single Index Measure Functions of Uncertainty Measure. In the light of the concept of single index measure function, the classification standard in Table 1, and the monitoring data in Table 2, the single index measure functions are constructed by linear measure functions most widely used in this paper. Figures 1-8 show the specific single index measure functions for all evaluation indexes, respectively.

In the light of single index measure functions mentioned in Figures 1-8 and combined with the monitoring data in Table 2, the single index evaluation matrix of Hanqiao coal mine of Jiawang in Xuzhou is calculated as follows:

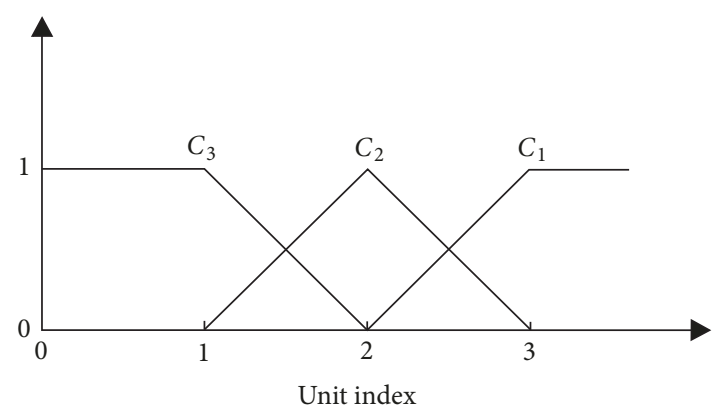

FIgURE 1: Single index measure function of qualitative indexes.

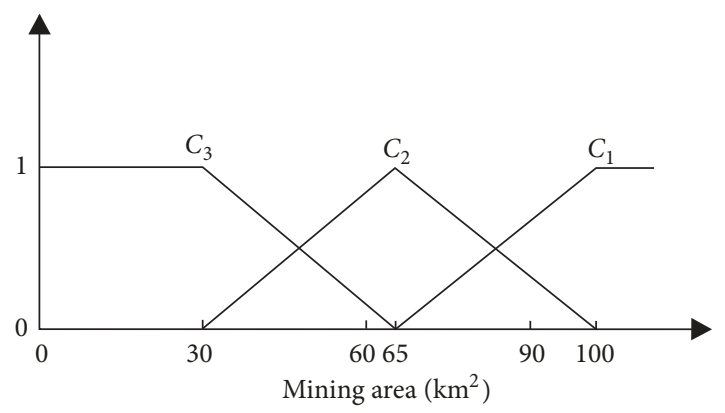

Figure 2: Single index measure function of mining area.

$$
\mu_{A_{1}}=\left[\begin{array}{lll}
0 & 0 & 1 \\
1 & 0 & 0 \\
1 & 0 & 0 \\
0 & 1 & 0 \\
1 & 0 & 0 \\
0 & 0 & 1 \\
1 & 0 & 0 \\
1 & 0 & 0 \\
1 & 0 & 0 \\
0 & 0 & 1 \\
0 & 0 & 1 \\
1 & 0 & 0 \\
1 & 0 & 0 \\
1 & 0 & 0 \\
1 & 0 & 0
\end{array}\right]
$$

3.2. Determination of Index Weights. In the study, according to the established evaluation index system of groundwater pollution risk in abandoned mines, the weights of all indexes are calculated by AHP. Similarly, using the entropy weight method, the weights of all indexes are calculated. Finally, combining the index weights obtained by AHP and the entropy method, the optimal weight coefficients $a_{1}^{*}=0.9748$ and $a_{2}^{*}=0.0252$ are calculated according to (6) and (7), and all the index weights are obtained based on the combined 
TABLE 1: Classification standard of groundwater pollution risk evaluation index for abandoned mines.

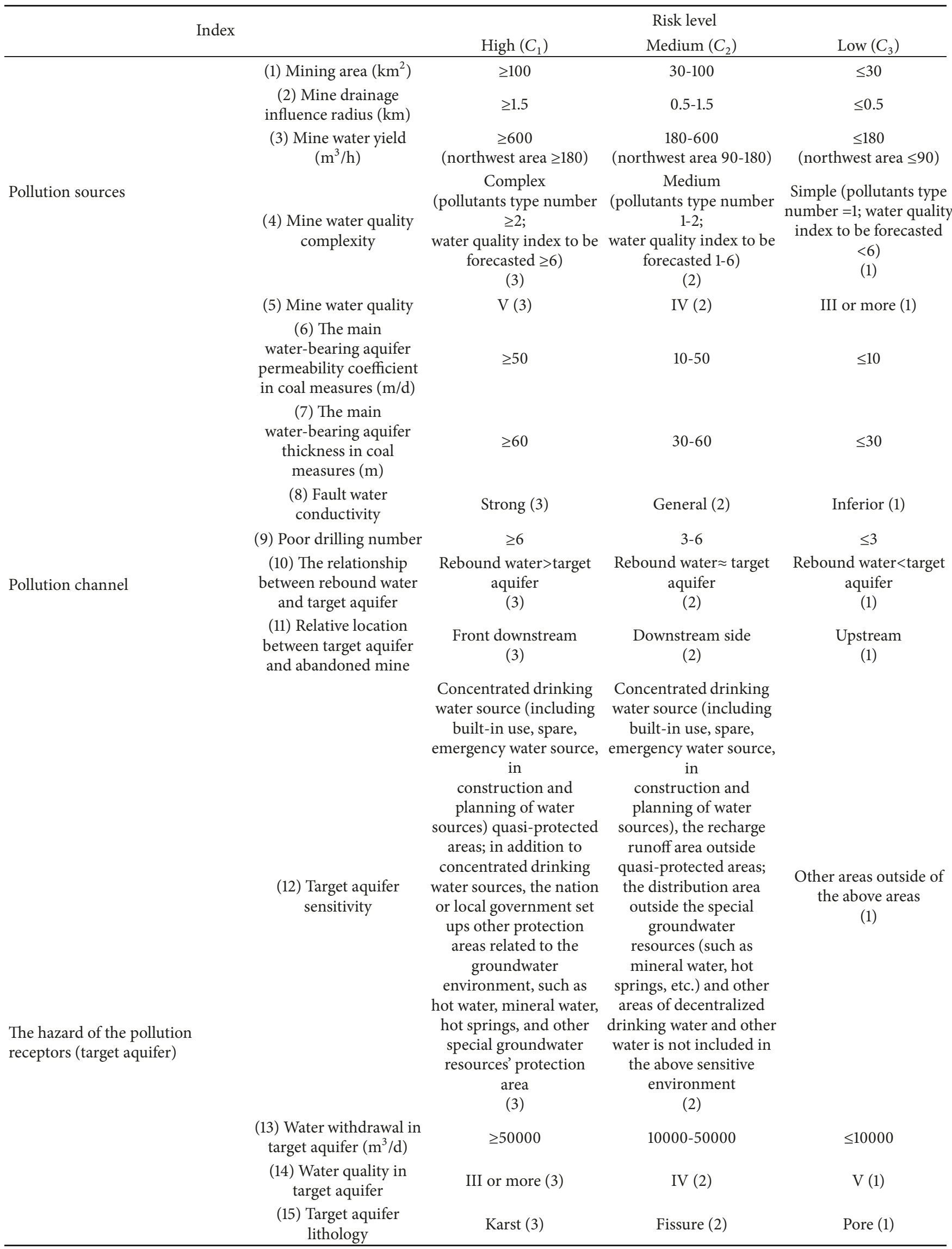


TABLE 2: Survey statistics table of evaluation index.

\begin{tabular}{|c|c|c|}
\hline Index & & Evaluation data in Hanqiao coal mine \\
\hline \multirow{5}{*}{ Pollution sources } & (1) Mining area $\left(\mathrm{km}^{2}\right)$ & 21 \\
\hline & (2) Mine drainage influence radius $(\mathrm{km})$ & $>2$ \\
\hline & (3) Mine water yield $\left(\mathrm{m}^{3} / \mathrm{h}\right)$ & $>3000$ \\
\hline & (4) Mine water quality complexity & $\begin{array}{l}\text { Pollutants type number } \geq 2 \text {; } \\
\text { Water quality index to be forecasted }<6\end{array}$ \\
\hline & (5) Mine water quality & $\mathrm{V}$ \\
\hline \multirow{6}{*}{ Pollution channel } & $\begin{array}{l}\text { (6) The main water-bearing aquifer } \\
\text { permeability coefficient in coal measures } \\
(\mathrm{m} / \mathrm{d})\end{array}$ & 9.5 \\
\hline & $\begin{array}{l}\text { (7) The main water-bearing aquifer } \\
\text { thickness in coal measures (m) }\end{array}$ & $>60$ \\
\hline & (8) Fault water conductivity & Strong \\
\hline & (9) Poor drilling number & $>6$ \\
\hline & $\begin{array}{l}\text { (10) The relationship between rebound } \\
\text { water and target aquifer }\end{array}$ & Under \\
\hline & $\begin{array}{l}\text { (11) Relative location between target } \\
\text { aquifer and abandoned mine }\end{array}$ & Upstream \\
\hline \multirow{4}{*}{ The hazard of the pollution receptors (target aquifer) } & (12) Target aquifer sensitivity & Concentrated drinking water source \\
\hline & $\begin{array}{l}\text { (13) Water withdrawal in target aquifer } \\
\qquad\left(\mathrm{m}^{3} / \mathrm{d}\right)\end{array}$ & 64000 \\
\hline & (14) Water quality in target aquifer & I-III \\
\hline & (15) Target aquifer lithology & Karst \\
\hline
\end{tabular}

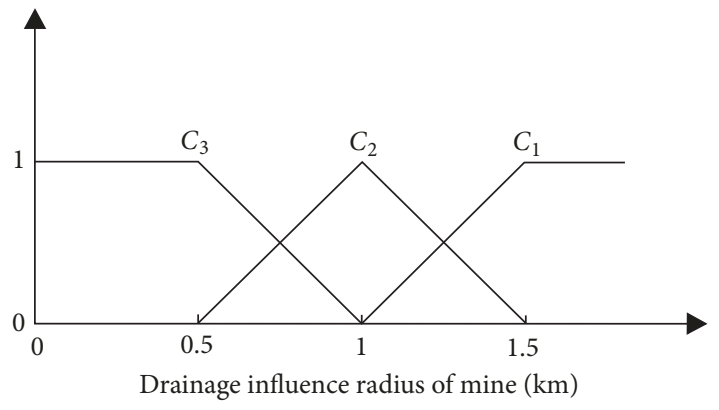

FIGURE 3: Single index measure function of mine drainage influence radius.

weighting of game theory. The calculation results are shown in Table 3.

From Table 3, the weight obtained by AHP fluctuates greatly, because the method is influenced by the expert subjective factors, highlighting the main factors involved in the indexes, ignoring the influence of some minor factors, which also directly affects the accuracy of the evaluation results. The weight obtained by entropy method has less fluctuation, because the method relies too much on the original sample data, but the original sample data is usually not very different, resulting in a relatively small difference in the weight distribution, and the weight obtained by this method also lacks accuracy. The weight obtained by game theory is located between the two, and the weight gap between the indexes has achieved a balance, which has reduced the impact of ignoring some minor factors and expert experience. An

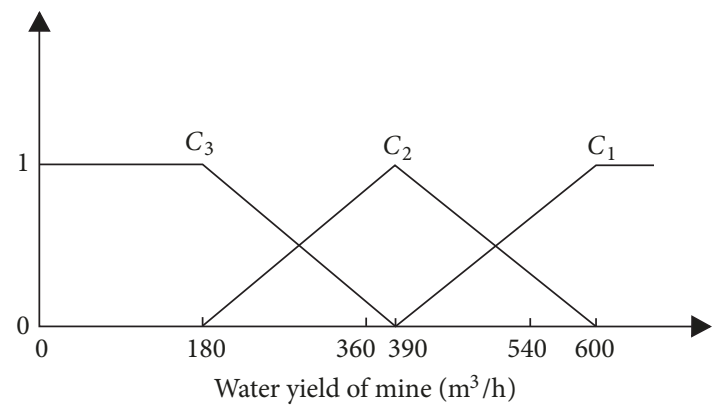

FiguRE 4: Single index measure function of mine water yield.

optimal weight of balance subjective and objective results is obtained.

3.3. Multiple Index Measure Evaluation Matrix Calculation. In the light of single index measure matrix and multiple index calculation formula, the multiple index vector is $\mu_{1}=\omega_{1}$. $\mu_{A_{1}}=\left\{\begin{array}{lll}0.65 & 0.14 & 0.21\end{array}\right\}$.

3.4. Credible Degree Recognition. According to the improved credible degree recognition formula (9), the optimized uncertainty measure distances $d_{1}=0.43, d_{2}=1.10$, and $d_{3}=$ 1.03 are obtained. Hence, the grade of Hanqiao coal mine is determined to be Class I (high risk). In order to verify the feasibility and accuracy of the model, the credible degree $\lambda$ is taken as $0.6,0.7,0.8$, and 0.9 , respectively, and compared with the attribute recognition optimization model by the 
TABLE 3: The weight of indexes.

\begin{tabular}{|c|c|c|c|c|}
\hline \multicolumn{2}{|c|}{ Index } & $\begin{array}{c}\text { The weight calculated by } \\
\text { AHP }\end{array}$ & $\begin{array}{l}\text { The weight calculated by } \\
\text { entropy weight }\end{array}$ & $\begin{array}{c}\text { The weight calculated by } \\
\text { game weight }\end{array}$ \\
\hline \multirow{4}{*}{ Pollution sources } & (1) Mining area $\left(\mathrm{km}^{2}\right)$ & 0.0724 & 0.067 & 0.0723 \\
\hline & $\begin{array}{c}\text { (2) Mine drainage } \\
\text { influence radius }(\mathrm{km})\end{array}$ & 0.0781 & 0.067 & 0.0778 \\
\hline & $\begin{array}{l}\text { (3) Mine water yield } \\
\left(\mathrm{m}^{3} / \mathrm{h}\right)\end{array}$ & 0.0651 & 0.067 & 0.0651 \\
\hline & $\begin{array}{l}\text { (4) Mine water quality } \\
\text { complexity }\end{array}$ & 0.1399 & 0.067 & 0.1381 \\
\hline \multirow{7}{*}{ Pollution channel } & (5) Mine water quality & 0.1271 & 0.067 & 0.1256 \\
\hline & $\begin{array}{l}\text { (6) The main } \\
\text { water-bearing aquifer } \\
\text { permeability coefficient } \\
\text { in coal measures }(\mathrm{m} / \mathrm{d})\end{array}$ & 0.0365 & 0.067 & 0.0373 \\
\hline & $\begin{array}{l}\text { (7) The main } \\
\text { water-bearing aquifer } \\
\text { thickness in coal } \\
\text { measures }(\mathrm{m})\end{array}$ & 0.0362 & 0.067 & 0.0370 \\
\hline & $\begin{array}{l}\text { (8) Fault water } \\
\text { conductivity }\end{array}$ & 0.0387 & 0.067 & 0.0394 \\
\hline & (9) Poor drilling number & 0.0278 & 0.067 & 0.0288 \\
\hline & $\begin{array}{l}\text { (10) The relationship } \\
\text { between rebound water } \\
\text { and target aquifer }\end{array}$ & 0.0559 & 0.067 & 0.0562 \\
\hline & $\begin{array}{l}\text { (11) Relative location } \\
\text { between target aquifer } \\
\text { and abandoned mine }\end{array}$ & 0.0447 & 0.067 & 0.0453 \\
\hline \multirow{4}{*}{$\begin{array}{l}\text { The hazard of the pollution } \\
\text { receptors (target aquifer) }\end{array}$} & $\begin{array}{l}\text { (12) Target aquifer } \\
\text { sensitivity }\end{array}$ & 0.076 & 0.067 & 0.0758 \\
\hline & $\begin{array}{l}\text { (13) Water withdrawal in } \\
\text { target aquifer }\left(\mathrm{m}^{3} / \mathrm{d}\right)\end{array}$ & 0.0558 & 0.067 & 0.0561 \\
\hline & $\begin{array}{l}\text { (14) Water quality in } \\
\text { target aquifer }\end{array}$ & 0.0837 & 0.067 & 0.0833 \\
\hline & $\begin{array}{l}\text { (15) Target aquifer } \\
\text { lithology }\end{array}$ & 0.0621 & 0.067 & 0.0622 \\
\hline
\end{tabular}

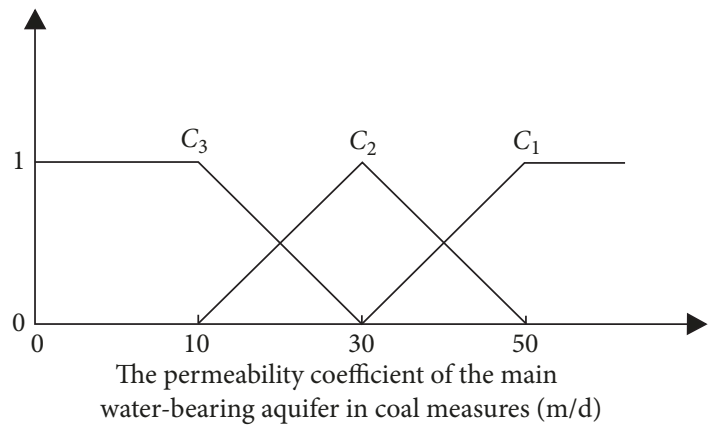

FIGURE 5: Single index measure function of the main water-bearing aquifer permeability coefficient in coal measures.

distance discriminant. When the credible degree $\lambda$ is taken as 0.6 and $k_{0}=0.65>0.6$, the grade of Hanqiao coal mine is determined to be Class I (high risk); when the credible degree $\lambda$ is taken as 0.7 and $k_{0}=0.79>0.7$, the grade of Hanqiao coal mine is determined to be Class II (medium

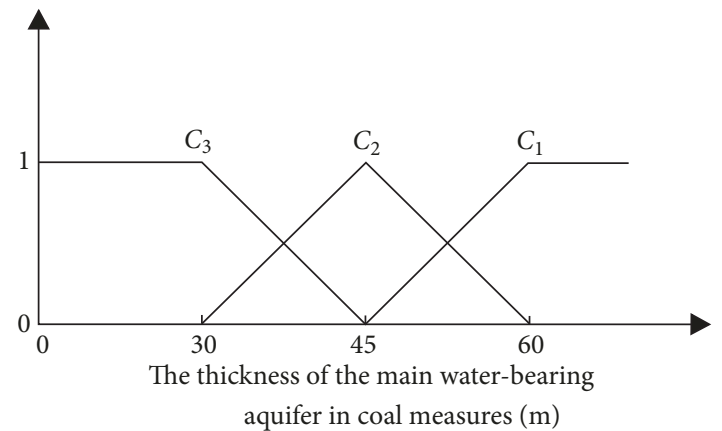

FIGURE 6: Single index measure function of the main water-bearing aquifer thickness in coal measures.

risk); when the credible degree $\lambda$ is taken as 0.8 or 0.9 and $k_{0}=1>0.8$ or 0.9 , the grade of Hanqiao coal mine is determined to be Class III (low risk). The results show that when the credible degree $\lambda$ is different, it has a great influence on the accuracy of the discriminant results. And the result is 


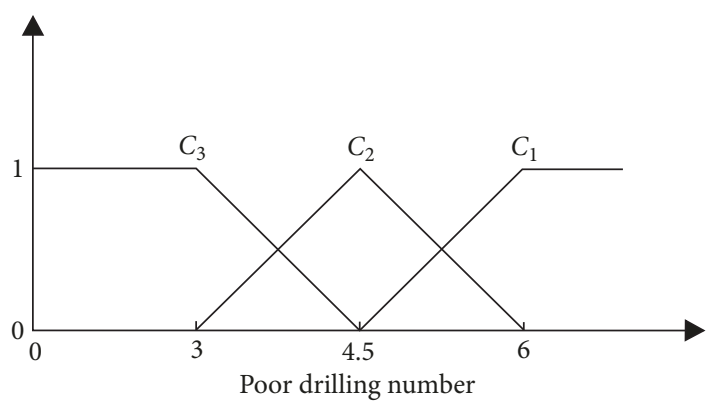

Figure 7: Single index measure function of poor drilling number.

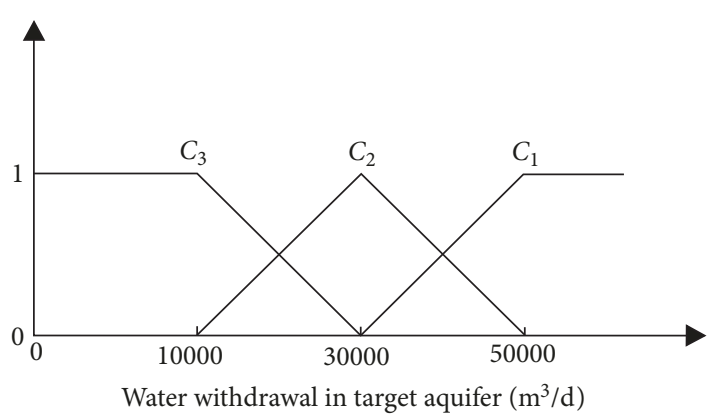

FIGURE 8: Single index measure function of water withdrawal in target aquifer.

compared with the evaluation result of Ting Li [24] who used AHP-fuzzy comprehensive evaluation method. The results are consistent, so it is feasible and accurate to predict the risk level of groundwater pollution in abandoned mines using the game theory and improved uncertainty measure model.

\section{Conclusions}

Analyzing the weight solving model and confidence recognition criteria in the uncertainty measure theory, based on the existing subjective and objective weight solving models, the optimal weight was determined by the idea of game theory. Based on the idea of the minimum uncertainty measure distance, the credible degree recognition criterion was improved, and a game theory-improved uncertainty measure optimization model was proposed. The example shows that the game theory-improved uncertainty measure evaluation model is more scientific, objective, and reasonable and deserves further study.

\section{Data Availability}

The data used to support the findings of this study are included within the article.

\section{Conflicts of Interest}

The authors declare that there are no conflicts of interest regarding the publication of this paper.

\section{Acknowledgments}

This work was financially supported by the open fund for State Key Laboratory of Water Resources Protection and Utilization in Coal Mining (SHJT-16-30.19) and the Special Fund for Basic Scientific Research of Central Colleges (310827173702).

\section{References}

[1] G. Y. Wang, "Unascertained information and its mathematical treatment," Journal of Harbin Architecture and Engineering Institute, vol. 23, no. 4, pp. 52-58, 1990.

[2] Y. C. Wan, Research on the Methods And Applications of Forecasting and Decision Making Based on Uncertainty, Southeast University, Nanjing, China, 2004.

[3] Y. J. Guo, Theory, Methods and Application of Comprehensive Evaluation, Science Press, Beijing, China, 2005.

[4] S. D. Wei and X. Q. Jiang, "A single-factor fuzzy evaluation method of using information entropy to determine the property weights," Computer Engineering Science, vol. 32, no. 7, pp. 93-95, 2010.

[5] Y. X. Liu, S. Liu, and W. Y. Wang, "Computation of weight in AHP and its application," Journal of Shenyang University (Natural Science, vol. 26, no. 5, pp. 372-375, 2014.

[6] C. L. Hwang and K. Yoon, Multiple Attribute Decision Making: Methods and Applications, vol. 186, Springer, Heidelberg, Germany, 1981

[7] X. Z. Zhang and G. Y. Chen, "Integrated AHP with Delphi to decide the index weights in vendor evaluation," Logistics Technology, vol. no. 9, pp. 71-74, 2005.

[8] Q. K. Cao, K. Z. Liu, and B. W. Zhang, "Calculation method of objective index weight by entropy," Journal of Hebei Institute of Architectural Science and Technology, vol. 17, no. 3, pp. 40-42, 2000.

[9] H. H. Yan, Y. X. Chen, S. M. Xu, and W. S. Yang, "Expert scoring mechanism and optimal evaluation model," System EngineeringTheory Practice, vol. 9, no. 2, pp. 19-23, 1989.

[10] Z. D. Sun and Z. S. Xu, "A model based on alternative similarity scale for uncertain multi-attribute decision-making," Chinese Journal of Management Science, vol. 9, no. 6, pp. 58-62, 2001.

[11] J. Ma, Z.-P. Fan, and L.-H. Huang, "A Subjective and objective inter-gated approach to determining attribute weights," European Journal of Operational Research, vol. 112, no. 2, pp. 397-404, 1999.

[12] Y. Jiang, H. T. Shan, J. P. Yuan, R. J. Jia, and S. Z. Wang, "Evaluation of power transmission and transformation project based on improved AHP-entropy game theory empowerment," Measurement Control Technology, vol. 37, no. 6, pp. 121-125, 2018.

[13] H. Li, J. H. Ming, and X. F. Shi, "Cleaner production assessments of zinc smelting enterprise based on game theory and fuzzy comprehensive evaluation," Gold Science and Technology, vol. 26, no. 5, pp. 635-646, 2018.

[14] K. D. Liu, H. Q. Wu, and Y. J. Pang, Mathematics Treatment and Application of Uncertainty Information, Science Press, Beijing, China, 1999

[15] K. D. Liu, H. Q. Wu, and N. P. Wang, Uncertainty Mathematics, Huazhong University of Science and Technology Press, Wuhan, China, 1997.

[16] H. J. He, S. R. Su, J. X. Wang, and P. Li, "Study and application on comprehensive evaluation model of landslide hazard based on 
uncertainty measure theory," Journal of Central South University (Science and Technology), vol. 44, no. 4, pp. 1564-1570, 2013.

[17] H. He, Y. Yan, C. Qu, and Y. Fan, "Study and application on stability classification of tunnel surrounding rock based on uncertainty measure theory," Mathematical Problems in Engineering, vol. 2014, Article ID 626527, 5 pages, 2014.

[18] H. He, Y. Zhao, X. Yang, Y. Gao, and X. Wu, "Study and application of safety risk evaluation model for $\mathrm{CO}_{2}$ geological storage based on uncertainty measure theory," Mathematical Problems in Engineering, vol. 2015, Article ID 964204, 5 pages, 2015.

[19] H. He, Y. Zhao, Z. Zhang, Y. Gao, and L. Yang, "Prediction of coalbed methane content based on uncertainty clustering method," Energy Exploration \& Exploitation, vol. 34, no. 2, pp. 273-281, 2016.

[20] H. He, L. An, W. Liu, and J. Zhang, "Prediction model of collapse risk based on information entropy and distance discriminant analysis method," Mathematical Problems in Engineering, vol. 2017, Article ID 8793632, 8 pages, 2017.

[21] Y. N. Jin, X. B. Li, P. J. Liu, and Y. Guo, "Predictive liability of the rockburst classification based on the improved unascertained clustering model," Journal of Safety and Environment, vol. 17, no. 1, pp. 12-16, 2017.

[22] J. Fang, H. J. He, L. An, and G. Jin, "The evaluation of potential for the exploration and development of coalbed methane resources based on an improved uncertainty measure optimization model," Energy Exploration Exploitation, vol. 37, no. 1, pp. 315-331, 2018.

[23] A. P. Cheng, Y. T. Gao, M. W. Ji, and P. Wu, "Forecast of water inrush from coal floor based on uncertainty measure theory," Metal Mine, vol. 43, no. 8, pp. 157-161, 2014.

[24] T. Li, Study on Groundwater Pollution Risk Assessment of Abandoned Coal Mine, China University of Mining \& Technology, Xuzhou, China, 2014. 


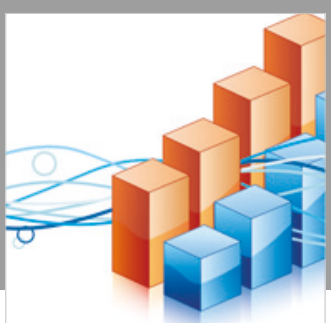

Advances in

Operations Research

\section{-n-m}
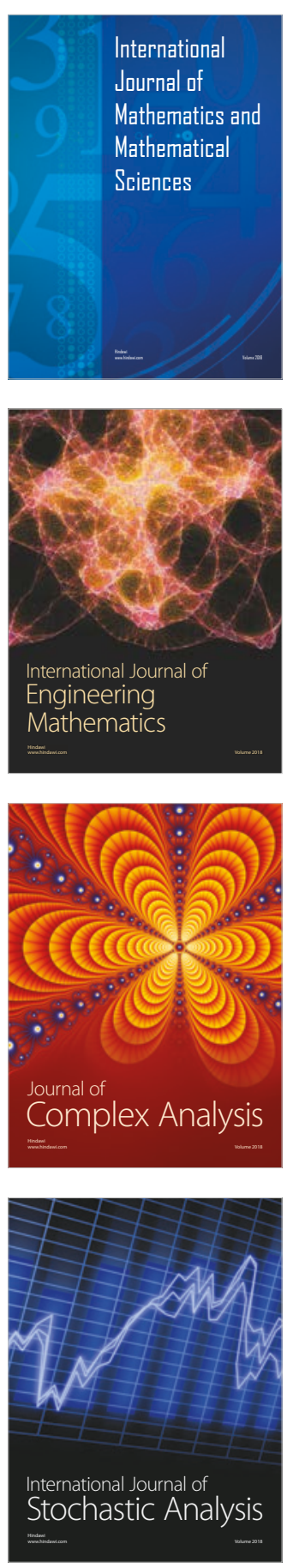
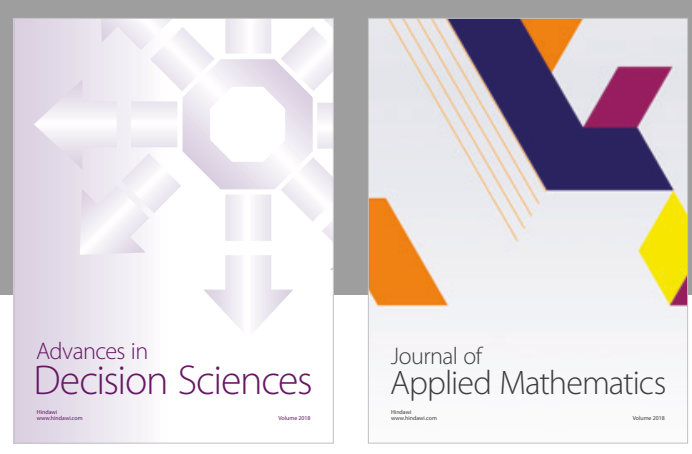

Journal of

Applied Mathematics
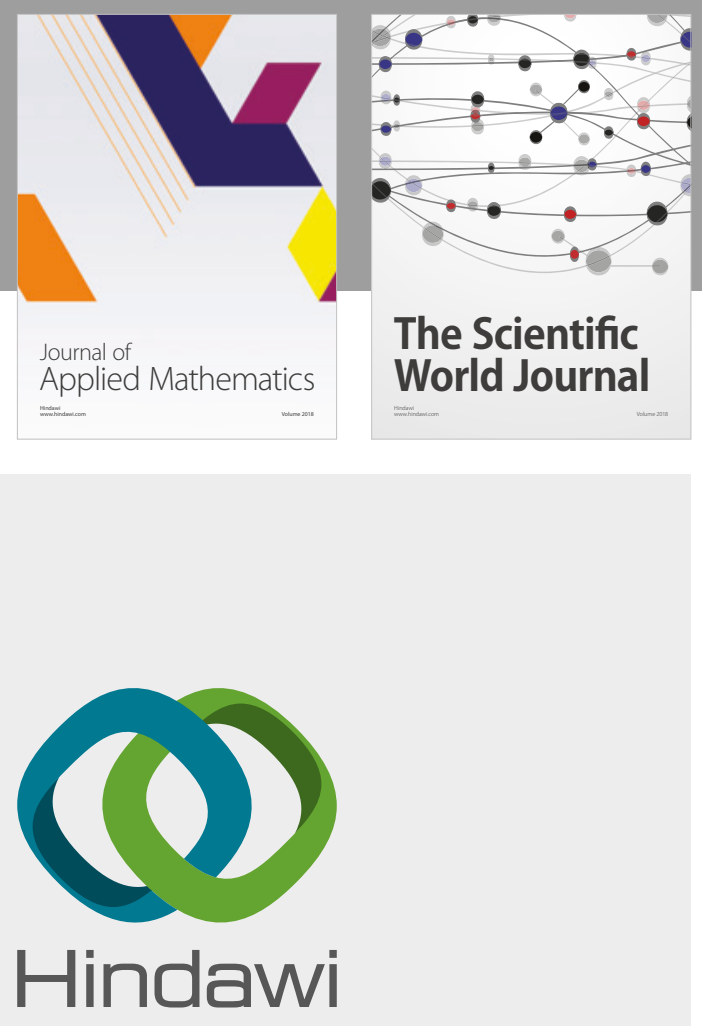

Submit your manuscripts at

www.hindawi.com

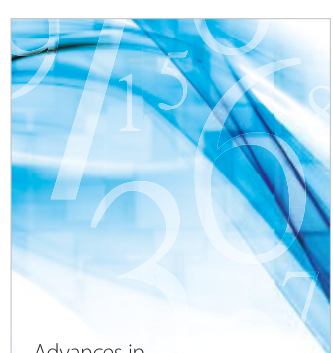

Advances in
Numerical Analysis
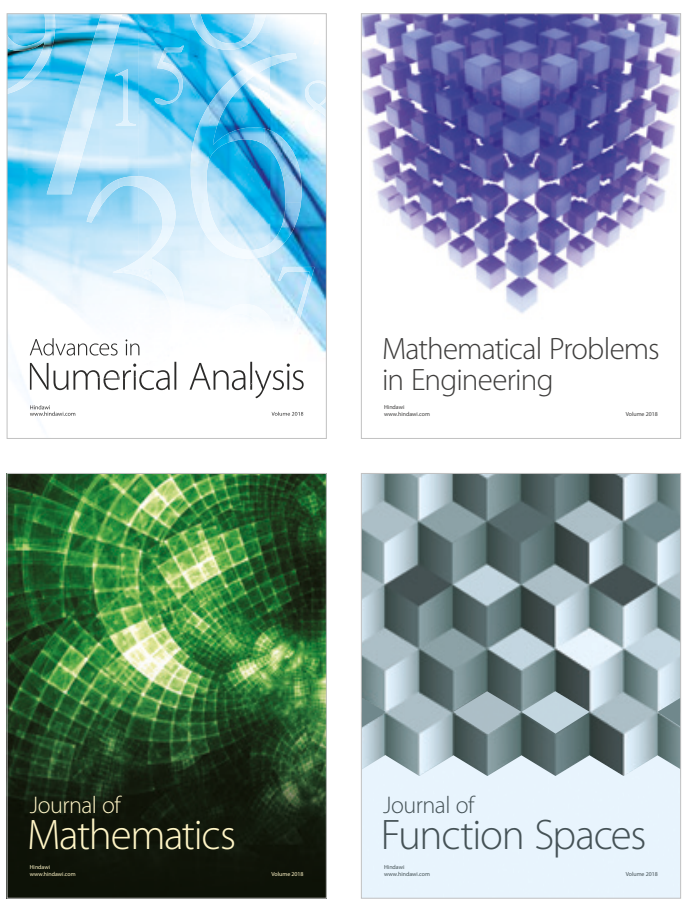

Mathematical Problems in Engineering

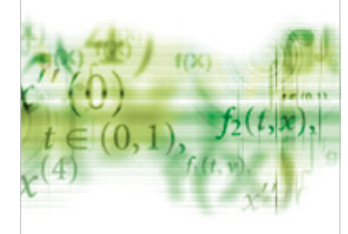

International Journal of

Differential Equations

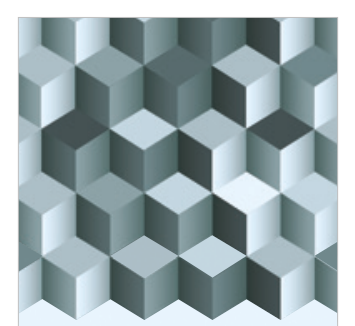

Journal of

Function Spaces

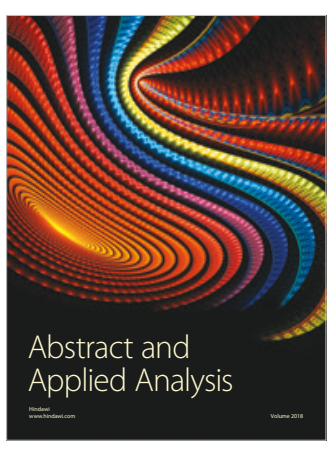

The Scientific

World Journal

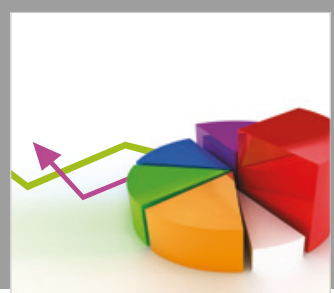

Journal of

Probability and Statistics
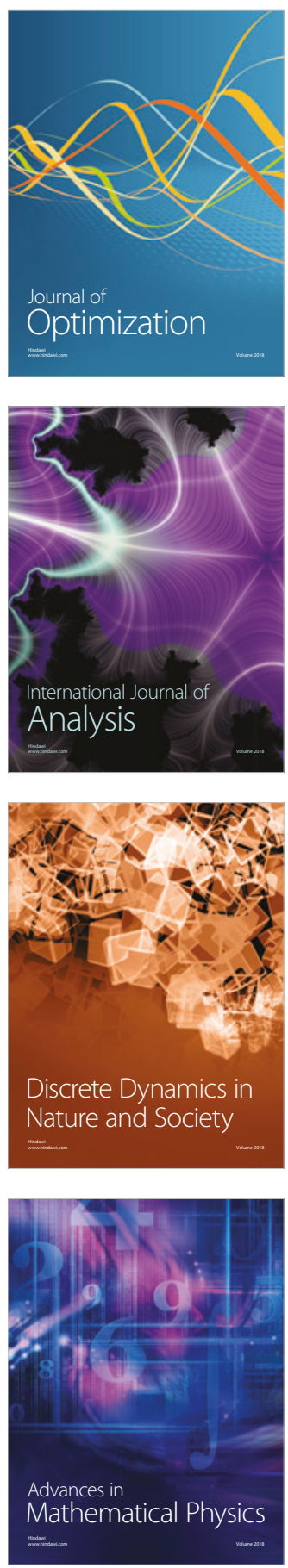